\title{
The Seasonal Footprinting Mechanism in the CSIRO General Circulation Models*
}

\author{
DANiel J. Vimont AND DAVID S. BATtisti \\ Department of Atmospheric Sciences, University of Washington, Seattle, Washington \\ ANTHONY C. HiRST \\ CSIRO Atmospheric Research, Aspendale, Victoria, Australia
}

(Manuscript received 27 March 2002, in final form 21 January 2003)

\section{ABSTRACT}

\begin{abstract}
An influence of midlatitude atmospheric variability on interannual ENSO and decadal ENSO-like variability is established and investigated in the Commonwealth Scientific and Industrial Research Organisation (CSIRO) coupled general circulation models (CGCMs). The effect of midlatitude atmospheric variability is felt in the Tropics via the previously hypothesized "seasonal footprinting mechanism" (SFM), in which a tropical circulation is forced during spring and summer by tropical SST anomalies that are generated by midlatitude atmospheric variability during the previous winter. The tropical circulation includes equatorial zonal wind stress anomalies that act as a stochastic forcing for the CSIRO CGCM's damped ENSO mode.

Details of the SFM are investigated herein. A temporal analysis indicates that the SFM may explain 20\%$40 \%$ of the model's interannual ENSO variability and nearly $70 \%$ of the model's decadal to interdecadal tropical variability. An analysis of the physical mechanisms that govern the SFM highlights the role of relaxed trade winds in producing tropical SST anomalies during winter, and identifies a weak positive coupled feedback between off-equatorial tropical SST anomalies and the atmospheric response to those anomalies.
\end{abstract}

\section{Introduction}

This study identifies and investigates a mechanism by which midlatitude atmospheric variability impacts tropical interannual ENSO and decadal ENSO-like variability in the Commonwealth Scientific and Industrial Research Organisation (CSIRO) coupled general circulation model (CGCM). This mechanism was originally identified by Vimont et al. (2001, hereafter VBH01) and labeled the "seasonal footprinting mechanism" (SFM). The current study provides a more detailed analysis of the SFM than was possible in VBH01.

\section{a. General background}

In an earlier study Vimont et al. (2002, hereafter VBH02) investigate the structure of, and dynamical processes responsible for, interannual and decadal ENSO variability in the CSIRO CGCM. They find that the CSIRO model is capable of reproducing many features

\footnotetext{
* Joint Institute for the Study of the Atmosphere and Ocean Contribution Number 902 .
}

Corresponding author address: Dr. Daniel J. Vimont, Dept. of Atmospheric Sciences, University of Washington, JISAO, Box 354235, Seattle, WA 98195-4235.

E-mail: dvimont@atmos.washington.edu of observed interannual and decadal variability in the tropical Pacific (see, e.g., Zhang et al. 1997; Wallace et al. 1998). Most notable is the close coupling between the atmosphere and ocean in the tropical Pacific, the eastward development of subsurface anomalies and standing oscillation at the surface [consistent with the findings of Wallace et al. (1998)], and the meridionally broadened spatial structure of decadal ENSO-like variability (Zhang et al. 1997). Still, the model's interannual ENSO amplitude is about half that observed (though the model's decadal variability has a similar amplitude to observed decadal ENSO-like variability) and exhibits a preferred periodicity (6-9 yrs) that is slightly longer than observed. VBH02 speculate that the CSIRO model's coarse ocean resolution introduces a damping on the ocean dynamics [consistent with the findings of $\mathrm{Ng}$ and Hsieh (1994)], which may explain the reduced amplitude and lengthened period of the model's ENSO variability.

VBH02 find that the spatial and temporal structure of interannual and decadal variability in the CSIRO CGCM is governed by coupled equatorial dynamics. The model's interannual ENSO variability proceeds via the so-called delayed oscillator mechanism [i.e., equatorial coupled ocean-atmosphere dynamics; see Neelin et al. (1998) for a review]. Delayed oscillator theory may be interpreted as the statement that an ENSO event, 
once initiated, contains within it a means for its own amplification (the positive coupled "Bjerknes feedback") as well as the seeds of its own destruction some time later (the negative "ocean memory" feedback). Through the delayed oscillator mechanism, coupled dynamics produces the spatial structure of the interannual variability and defines the interannual timescale (Thompson and Battisti 2001). VBH02 find that interannual ENSO variability in the CSIRO model involves both the positive Bjerknes feedback and the negative ocean memory feedback. VBH02 also find that the role of coupled dynamics in producing decadal ENSO-like variability is fundamentally different than that for interannual timescales. Although the positive Bjerknes feedback is operative, the negative ocean memory feedback is much weaker, or absent on decadal timescales. As a result, any decadal perturbation in the Tropics will be amplified (via the positive Bjerknes feedback) and should produce a similar "ENSO-like" spatial structure of variability.

The role of stochastic forcing in the generation of tropical interannual variability depends on the linear stability of the ENSO mode. In the linearly unstable regime [e.g., the early model studies of Zebiak and Cane (1987), Battisti (1988), Schopf and Suarez (1988)] interannual ENSO variance is maintained by the instability of the ENSO mode itself; stochastic forcing may be added to these models, but its presence is not necessary for maintaining ENSO variance. More recently, Thompson and Battisti (2001) have used a linearized version of the Battisti (1988) model to show that, under a wide and realistic range of parameter space, the leading Floquet mode (Thompson and Battisti, 2000) is the linearly decaying, oscillatory ENSO mode. In this linearly stable regime stochastic forcing plays a crucial role in sustaining interannual ENSO variability, as well as producing decadal variance in the Tropics (see also Penland and Sardeshmukh 1995; Chang et al. 1996; Moore and Kleeman 1999). VBH02 find that the behavior of the CSIRO model's interannual ENSO variability suggests that the tropical variability in the CSIRO CGCM falls into a heavily damped, linearly stable regime. Various mechanisms have been hypothesized as important sources of tropical stochastic forcing, including the Madden-Julian oscillation [see Zhang et al. (2001) for a summary], random fluctuations that project onto ENSO's optimal (Penland and Sardeshmukh 1995) and midlatitude atmospheric variability (Barnett et al. 1999; Pierce et al. 2000; VBH01). The results presented in the following sections identify the latter as a particularly effective component of the stochastic forcing of ENSO in the CSIRO CGCM.

VBH01 identify the SFM-a mechanism by which intrinsic midlatitude atmospheric variability affects the tropical ENSO variability-in the CSIRO CGCM. The SFM operates as follows. During winter, midlatitude atmospheric variability imparts an SST "footprint" onto the ocean surface via changes in the net surface heat flux. The SST anomaly persists into the spring and summer season, and in the Tropics and subtropics, forces a residual atmospheric circulation that includes zonal wind stress anomalies along the equator. These equatorial zonal wind stress anomalies (generated through the SFM) are a source of stochastic forcing for the model's tropical ENSO variability. We note that the modeling studies of Barnett et al. (1999) and Pierce et al. (2000) demonstrate behavior that is not inconsistent with the results presented in VBH01 and herein. Vimont et al. (2003) demonstrate that the SFM appears to be operative in the observed record.

\section{b. Outline}

This study identifies and investigates the physical processes inherent to the SFM in more detail than was possible in VBH01. A brief description of the CSIRO models is presented in section 2 . Section 3 presents the spatial and temporal structure of the leading mode of midlatitude atmospheric variability over the North Pacific in the CSIRO CGCMs. In section 4 the seasonal relationships that compose the SFM are presented in three different model configurations. Section 5 identifies and examines the physical processes responsible for the SFM, and a discussion of the results is presented in section 6 .

\section{Model and data}

We investigate the seasonal footprinting mechanism by using three configurations of the CSIRO general circulation model. Each configuration consists of the CSIRO atmosphere, land, and sea ice models coupled to a different representation of an ocean. In the first (the ATM simulation; Watterson 2001), the atmosphere, land, and sea ice models are forced by the annually varying SST climatology. The second simulation (the MIX simulation; Watterson et al. 1997) parameterizes the ocean as a constant 50-m slab, with no ocean dynamics. In last simulation (the DYN simulation; Hirst et al. 2000), a full dynamic ocean general circulation model is coupled to the atmosphere, land, and sea ice models. In the MIX and DYN simulations, the coupling is interactive, allowing the atmosphere to respond to any surface heat flux anomalies produced by the ocean. The ATM simulation is integrated for $500 \mathrm{yr}$, the MIX simulation for $470 \mathrm{yr}$, and the DYN simulation for 1000 yr. All integrations were performed at CSIRO. The spinup procedure for the DYN simulation is described in Gordon and O'Farrell (1997). Flux adjustments are applied to the MIX and DYN simulations and are described for the DYN simulation in Gordon and O'Farrell (1997). For reference, the details of each simulation are presented in Table 1.

The atmospheric component of the CSIRO climate model is spectral, with rhomboidal truncation at 21 wavenumbers (R21). This corresponds to a physical grid 
TABLE 1. Description of CSIRO model simulations.

\begin{tabular}{clrl}
\hline \hline Simulation & \multicolumn{1}{c}{ Ocean } & Duration & \multicolumn{1}{c}{ Reference } \\
\hline ATM & Repeating annual cycle of SST & $500 \mathrm{yr}$ & Watterson (2001) \\
MIX & 50-m mixed layer; no ocean dynamics & $470 \mathrm{yr}$ & Watterson et al. (1997) \\
DYN & $3.2^{\circ}$ lat $\times 5.6^{\circ}$ lon, 21-level dynamic ocean model & $1000 \mathrm{yr}$ & Hirst et al. (2000) \\
\hline
\end{tabular}

of about $3.2^{\circ}$ latitude by $5.6^{\circ}$ longitude. The vertical dimension is represented by nine sigma levels. The model has annual and diurnal cycles and is integrated with a time step of $30 \mathrm{~min}$. Convection is parameterized by a moist convective adjustment scheme that generates mass flux and the cloud parameterization is based on relative humidity. A more complete description of the atmospheric model and a description of the land surface model can be found in Gordon and O'Farrell (1997). The sea ice model is described in O'Farrell (1998).

The dynamic ocean model used in the DYN simulation is based on the Bryan-Cox code (Cox 1984). The ocean model's horizontal resolution matches the atmospheric model's physical grid $\left(3.2^{\circ}\right.$ latitude by $5.6^{\circ}$ longitude) and has 21 vertical levels. The effect of coarse ocean model resolution on equatorial dynamics is discussed in VBH02. The ocean's interior vertical diffusivity is calculated as a function of stratification (Gargett 1984), though with a default minimum set at $0.3 \mathrm{~cm}^{2} \mathrm{~s}^{-1}$. To simulate a surface mixed layer, this default minimum is raised to $20 \mathrm{~cm}^{2} \mathrm{~s}^{-1}$ between levels 1 and 2 (at $25 \mathrm{~m}$ ) and $1 \mathrm{~cm}^{2} \mathrm{~s}^{-1}$ between levels 2 and 3 (at $50 \mathrm{~m}$ ). The effect of oceanic mesoscale eddies on tracer transport is parameterized using the scheme of Gent and McWilliams (1990). A more complete description of the ocean model is provided in Hirst et al. (2000). As described earlier, an analysis of the tropical variability in the DYN simulation was performed by VBH02.

\section{Midlatitude variability}

The SFM provides a mechanism by which midlatitude atmospheric variability can affect the Tropics. Important to this mechanism are the details of variability in the midlatitudes. This section presents the spatial and temporal structure of the leading mode of midlatitude atmospheric variability from the three model simulations.

Statistical modes of midlatitude atmospheric variability are defined by applying empirical orthogonal function-principal component (EOF-PC) analysis to the boreal winter averaged (November-March, hereafter NDJFM) sea level pressure (SLP) over the North Pacific (defined over the region $15^{\circ}-90^{\circ} \mathrm{N}, 110^{\circ} \mathrm{E}-90^{\circ} \mathrm{W}$ ). The data are detrended and standardized, and the EOF-PC analysis is applied to the SLP correlation matrix. The leading statistical mode resulting from the EOF-PC analysis explains $21.5 \%, 26.8 \%$, and $27.2 \%$ of the variability in the ATM, MIX, and DYN simulations, respectively, and is generally well separated from the second modes $(16.2 \%, 13.3 \%$, and $14.0 \%)$. The annually resolved (winter average) principal component time series for the leading mode of each simulation will be used to describe midlatitude atmospheric variability in each of the model simulations. Hereafter, this leading principal component will be referred to as PC1. Additionally, monthly indices (hereafter referred to as MPCs) are generated for each mode by projecting the SLP EOFs onto the nonstandardized monthly resolved SLP data for each simulation. The use of nonstandardized data allows a direct comparison of the variance (and variance spectra) between the MPCs for each model simulation.

Spatial correlations between SLP and PC1 from each respective simulation are shown in Fig. 1. The three maps are quite similar for each simulation (the spatial correlation between each of the EOFs is greater than 0.97) and depict a zonally elongated SLP dipole on either side of $50^{\circ} \mathrm{N}$. The pattern bears a strong resemblance to the North Pacific oscillation (NPO) discussed by Walker and Bliss (1932) and by Rogers (1981) [note that the term NPO used herein should not be confused with the North Pacific oscillation defined by Gershunov and Barnett (1998), which is a renaming of the Pacific decadal oscillation defined by Mantua et al. (1997)]. The accompanying upper-level circulation patterns (not shown) resemble the west Pacific teleconnection pattern, in accord with the observational results of Hsu and Wallace (1985). In the polarity depicted in Fig. 1, the NPO characterizes a blocking pattern over the Aleutian Islands, while in the opposite polarity it represents a strengthening and westward extension of the jet over the North Pacific (Rogers 1981; Hsu and Wallace 1985). Further description of the spatial structure of variability that accompanies PC1 is presented in section $4 \mathrm{a}$.

The seasonality of MPC1 from the DYN simulation is illustrated in Fig. 2. Figure 2 is generated by calculating variance of MPC1 (described above) from the DYN simulation as a function of calendar month (see Fig. 2 caption for details). Figure 2 (bars) shows that the NPO (as represented by MPC1) is most energetic during the northern winter months, and is virtually nonexistent during the northern summer. As expected, the same seasonality is seen in the monthly evolution of total midlatitude atmospheric variance (Fig. 2, solid line). Similar seasonal dependence is evident in the ATM and MIX simulations.

To further examine the temporal structure of midlatitude atmospheric variability in the three model simulations, we apply spectral analysis to the leading MPC from each of the model simulations, and to the monthly resolved cold tongue index (CTI) from the MIX and 


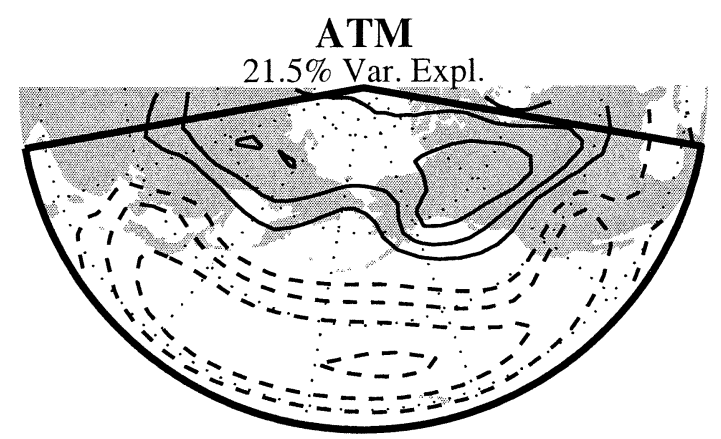

MIX

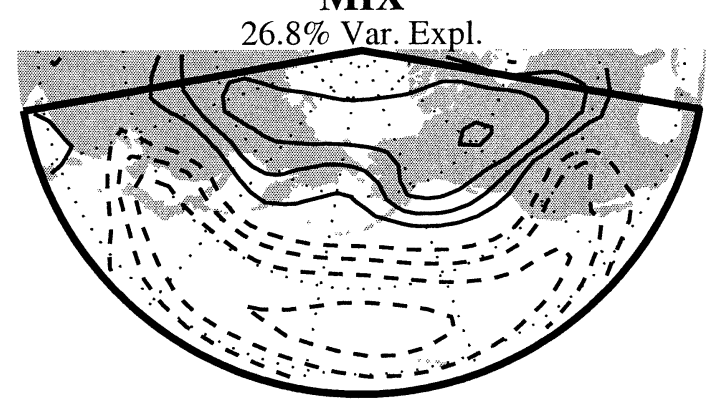

DYN

27.2\% Var. Expl.

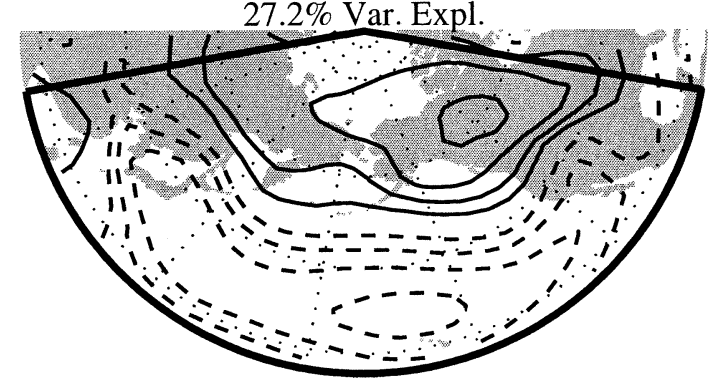

FIG. 1. Correlations between winter averaged (NDJFM) SLP and PC1 of SLP (see text for details): (top) ATM, (middle) MIX, and (bottom) DYN simulation. Contour interval is 0.2. Negative contours are dashed; the zero contour is omitted. The percent variance explained by the leading EOF is indicated at the top of each panel. The frames in each panel indicate the region over which the EOF-PC analysis is performed.

DYN simulations. The CTI is defined as SST averaged over the region $6^{\circ} \mathrm{S}-6^{\circ} \mathrm{N}, 180^{\circ}-90^{\circ} \mathrm{W}$, and is a commonly used index of ENSO variability (Mitchell and Wallace 2001, manuscript submitted to J. Climate; VBH02). We note that the CTI is somewhat meaningless in the MIX simulation, in which no ENSO variability is present. Spectra are calculated using a moving 50-yr Hanning window with a 25 -yr overlap. Thus, each spectral estimate has 20,18, and 40 degrees of freedom in the ATM, MIX, and DYN simulations, respectively. No statistical significance is claimed for any spectral estimate, aside from the 6-9-yr preferred periodicity for the DYN CTI, discussed in VBH02.

The variance spectra of MPC1 from each simulation are presented in Fig. 3a, and the total variance of MPC1

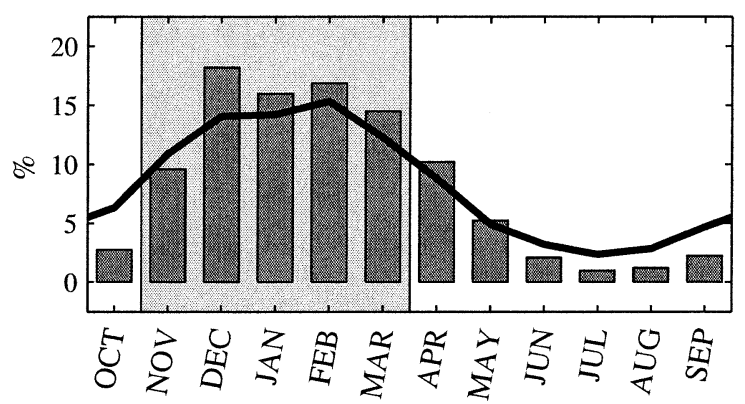

FIG. 2. Month-by-month variance of MPC1 from the DYN simulation (bars), and month-by-month total SLP variance (solid line). Variance is plotted as a percentage of the sum of MPC1 or SLP variance over all months. Months used to define the leading statistical modes of midlatitude SLP variability (via EOF-PC analysis) are highlighted by background shading.

from the MIX and DYN simulations are presented relative to the ATM simulation in Table 2. The spectra from the three simulations are in close agreement for periods shorter than a couple of years. For interannual to interdecadal timescales, the variance of MPC1 from the MIX and DYN simulations is more than twice that of the ATM simulation (see also Table 2). This increase in decadal variance is not observed in the higher-order MPCs [ratios for MPC2, which represents variability in the Aleutian low-Pacific North American (PNA) teleconnection (not shown), are listed in Table 2]. Still, the $e$-folding decay time of each of the MPC1 time series is less than a month, confirming that the bulk of the variance represents random, month-to-month variations of the NPO (note also the comparable total variance ratios in Table 2).
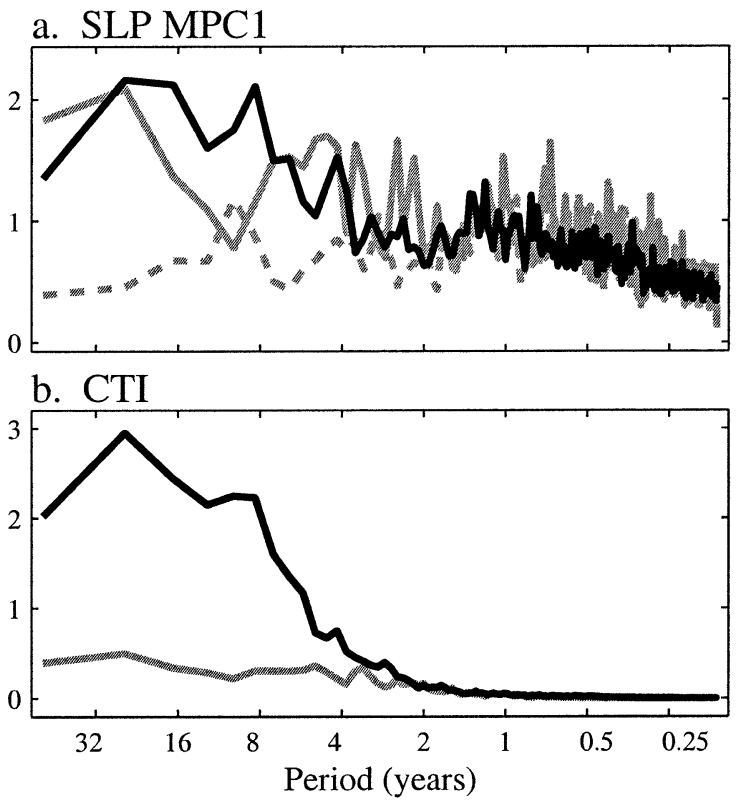

FIG. 3. Variance spectra of (a) MPC1 and (b) the CTI (see text) for the DYN (solid black lines), MIX (solid gray lines), and ATM simulations [dashed gray line in (a)]. 
TABLE 2. Variance ratios for MPC1 and MPC2. Variance is calculated as the integral of the spectra in Fig. 3 over the bands listed.

\begin{tabular}{lccccc}
\hline \hline \multirow{2}{*}{ Ratio } & \multicolumn{2}{c}{ MPC1 } & & \multicolumn{2}{c}{ MPC2 } \\
\cline { 2 - 3 } \cline { 5 - 6 } \cline { 5 - 6 } & Total & $(>4 \mathrm{yr})$ & & Total & $(>4 \mathrm{yr})$ \\
\hline MIX:ATM & 1.19 & $(2.26)$ & & 1.09 & $(1.01)$ \\
DYN:ATM & 1.06 & $(2.37)$ & & 1.00 & $(1.04)$ \\
DYN:MIX & 0.89 & $(1.05)$ & & 0.92 & $(1.03)$ \\
\hline
\end{tabular}

To further examine the source of decadal variance for MPC1 in the MIX and DYN simulations, the variance spectrum of the CTI from each simulation is presented in Fig. 3b. The spectra in Fig. 3 and variance ratios in Table 2 are consistent with the hypothesis of Barsugli and Battisti (1998), which attributes the increased decadal variance to reduced thermal damping of atmospheric and oceanic temperature anomalies at low frequencies. This conclusion is reached by noting that first, despite the increased variance of the CTI for the DYN simulation (Fig. 3b), MPC1 from both the MIX and DYN simulations exhibit similar levels of decadal variance (see Table 2). If this increased variance were due to tropical ENSO forcing, then MPC1 from the DYN simulation should exhibit considerably more decadal variance than MPC1 from the MIX simulation. Second, coupling to an interactive ocean amplifies the decadal variance of the first mode (the NPO) much more so than the second (the Aleutian low-PNA). This is consistent with the modeling results of Bladé $(1997,1999)$ (also suggested by Saravanan 1998), who finds that coupling tends to amplify the variance of the "zonal index" modes (such as the NPO) more so than the PNA. Thus, we conclude that the increased decadal variance for the leading SLP mode results from the reduced thermal damping hypothesis of Barsugli and Battisti (1998).

\section{The seasonal footprinting mechanism}

This section presents the seasonal relationships that compose the SFM. The section begins with a presentation of the spatial structure of variability associated with PC1 of midlatitude atmospheric variability during winter and summer, followed by an analysis of the temporal relationships between PC1 and tropical ENSO variability.

\section{a. Evolution of variability associated with PC1}

The spatial structure of the leading mode of North Pacific winter (NDJFM) atmospheric variability is revealed by regressing winter-averaged SLP, zonal wind stress, net surface heat flux (for the ATM simulation), and SST (for the MIX and DYN simulations) onto PC1 (defined in section 3). These regression maps are presented for each of the three simulations in Figure 4.

The patterns of winter SLP anomalies identified from the EOF-PC analysis in section 3 (shown in the top row of regression maps in Fig. 4) are remarkably similar in each of the model simulations. Not surprisingly, the regression maps bear a strong resemblance to the NPO exhibited in the correlation maps in Fig. 1. The largest SLP difference between the three model simulations is found in the northern lobe of the SLP dipole. In the MIX and DYN simulations, the northern lobe's amplitude is $50 \%-75 \%$ stronger than that of its counterpart in the ATM simulation. Additionally, the southern lobe of the SLP dipole amplifies slightly in the MIX and DYN simulations. The increased amplitude is consistent with the increased decadal variance in the MIX and DYN simulations in Fig. 3.

The winter zonal wind stress anomalies associated with PC1 are shown in the second row of Fig. 4. In all three simulations the midlatitudes exhibit a southward shift in the climatological midlatitude westerlies, consistent with the SLP regression maps. In the Tropics a weakening of the trades extends southward to about $10^{\circ} \mathrm{N}$ in the ATM simulation and to about $7.5^{\circ} \mathrm{N}$ in the MIX and DYN simulations. Though the zero contour has been omitted, both the ATM and MIX simulations produce weak easterly zonal wind stress anomalies along the equator (not visible in Fig. 4).

The third row of Fig. 4 depicts the regression maps of net surface heat flux (for the ATM simulation) and SST (for the MIX and DYN simulations) onto PC1 from each respective simulation. The spatial structure of the SST maps (the SST footprint of the NPO) from the MIX and DYN simulations consists of a tongue of negative SST anomalies extending eastward from the western ocean boundary along about $30^{\circ} \mathrm{N}$, flanked to the north and south by regions of positive SST anomalies. Positive subtropical SST anomalies extend from Baja California southwestward to the equator in both the MIX and DYN simulations. We note that the structure of equatorial SST anomalies bears little resemblance to the DYN simulation's ENSO variability (see VBH02). The net heat flux from the ATM simulation is similar in spatial structure to the SST maps from the MIX and DYN simulations, with downward heat flux anomalies in the ATM simulation coinciding with positive SST anomalies in the MIX and DYN simulations. This suggests that the NPO is forcing the SST footprint that is seen in the MIX and DYN simulations. The physics responsible for generating the SST footprint will be examined in more detail in section 5 a.

Regression maps of summer (May-September, hereafter MJJAS) averaged data onto the previous winter's PC1 from each respective simulation are shown in Fig. 5. Thus, Fig. 4 illustrates conditions that occur simultaneously with the NPO, while Fig. 5 illustrates conditions that occur during the following summer. Immediately obvious is the lack of variability during the summer months in the ATM simulation. This indicates that the winter-to-summer memory in the MIX and DYN simulations must arise from interactions with the ocean.

During the summer, SLP anomalies in the MIX and 

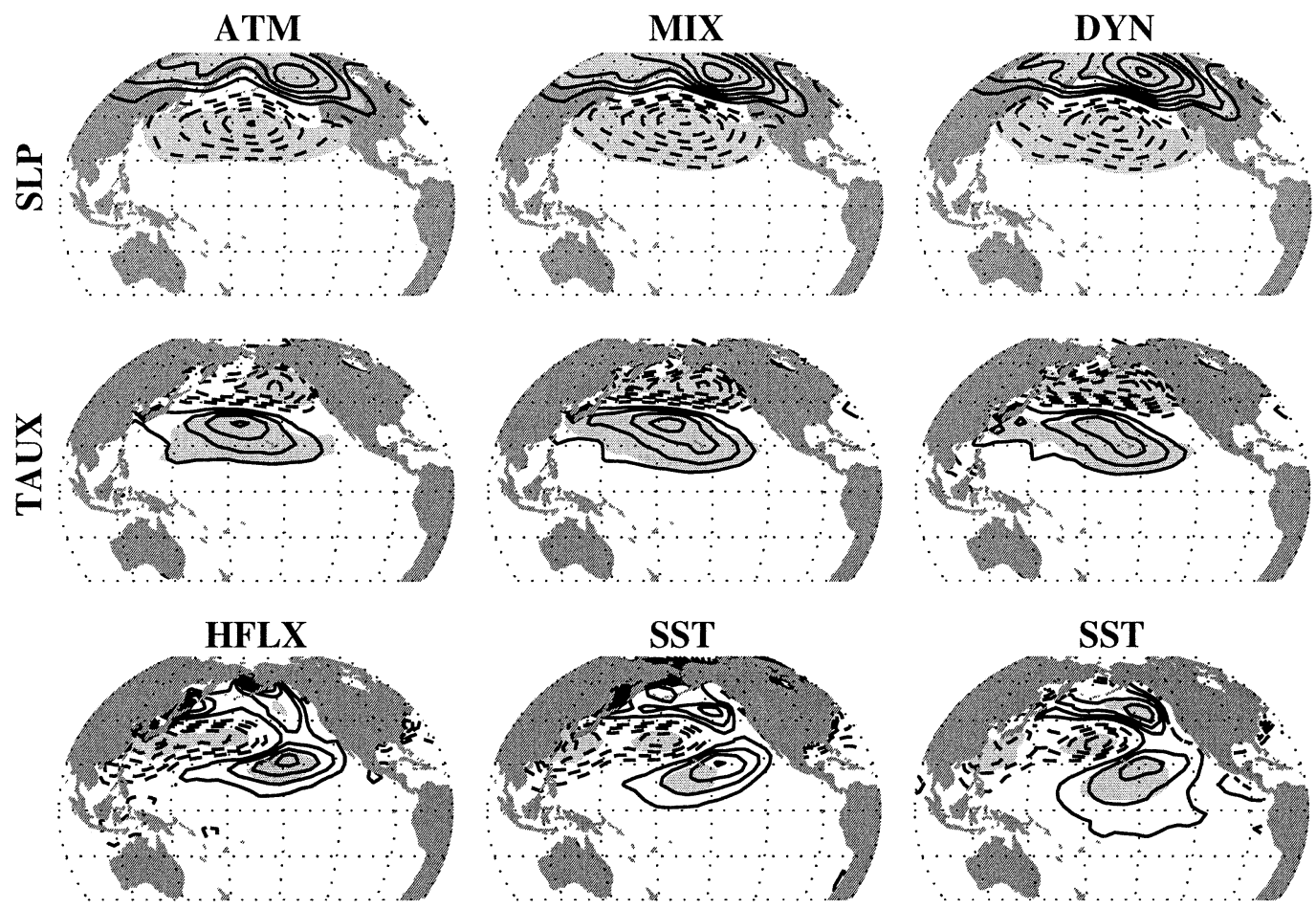

FIG. 4. Regressions of winter average (NDJFM) data onto PC1 from the (left) ATM, (middle) MIX, and (right) DYN simulations; (top) SLP, contour interval $0.4 \mathrm{hPa}$ (std dev) ${ }^{-1}$; (middle) zonal wind stress, contour interval 0.05 dyn $\mathrm{cm}^{-2}$ (std dev) $)^{-1}$; (bottom) net surface heat flux [ATM simulation, contour interval $3 \mathrm{~W} \mathrm{~m}^{-2}(\mathrm{std} \mathrm{dev})^{-1}$ ] and SST [MIX and DYN simulations, contour interval $0.075 \mathrm{~K}\left(\right.$ std dev) ${ }^{-1}$ ]. Light shading indicates regions where PC1 from the respective simulation explains more than $20 \%$ of the local variance of the respective data. Negative contours are dashed; the zero contour is omitted.

DYN simulations have a very different structure than that during the previous winter. In the midlatitudes SLP anomalies are quite weak and show no indication of a NPO-like pattern of variability. In the subtropics the summer circulation is characterized by an anomalous low pressure centered at the date line and $20^{\circ} \mathrm{N}$. The winter PC1 explains well over $10 \%$ of the local summer variance in the region of this anomalous low, confirming that the structure is not a statistical artifact. In the DYN simulation negative SLP anomalies extend along the equator from the date line to the eastern edge of the basin (note that although the contour interval is too large to show these anomalies clearly, the light gray shading indicates that PC1 explains more than $10 \%$ of the variance of equatorial SLP). Some equatorial symmetry is seen in both the MIX and DYN simulations, though it is much more pronounced in the DYN simulation.

Summer tropical zonal wind stress anomalies from the MIX and DYN simulations are consistent with the negative subtropical SLP anomalies during summer, with easterly anomalies to the north and a tongue of westerly anomalies to the south of the anomalous low pressure. The tongue of westerly tropical zonal wind stress anomalies along the southern flank of the subtropical low extends to the equator, in contrast to the winter zonal wind stress maps. The differing structure of winter and summer tropical zonal wind stress anomalies will be shown to have an important effect on the forcing of equatorial oceanic Kelvin waves (essential for producing ENSO variability) in section 5b. It is notable that the amplitude of summer zonal wind stress anomalies in the DYN simulation is about half that of the MIX simulation.

Finally, the regression maps of summer SST onto the previous winter's PC1 are shown for the MIX and DYN simulations in the bottom row of Fig. 5. The similar spatial structure between the winter and summer SST maps in the MIX simulation indicates that SST anomalies generated during the winter persist into the following summer season. One subtle difference between the summer and winter SST maps from the MIX simulation is the southwestward shift in the location of maximum tropical SST anomalies in the summer compared with that in winter. This southward migration will be explored in more detail in section $5 \mathrm{c}$.

The most striking difference between the summer variability in the DYN and MIX simulations is found in the summer SST maps. Like the MIX simulation, the DYN simulation exhibits a similar spatial structure in midlatitudes during both seasons. However, in the Tropics the summer SST anomalies in the DYN simulation bear a strong resemblance to the DYN simulation's 

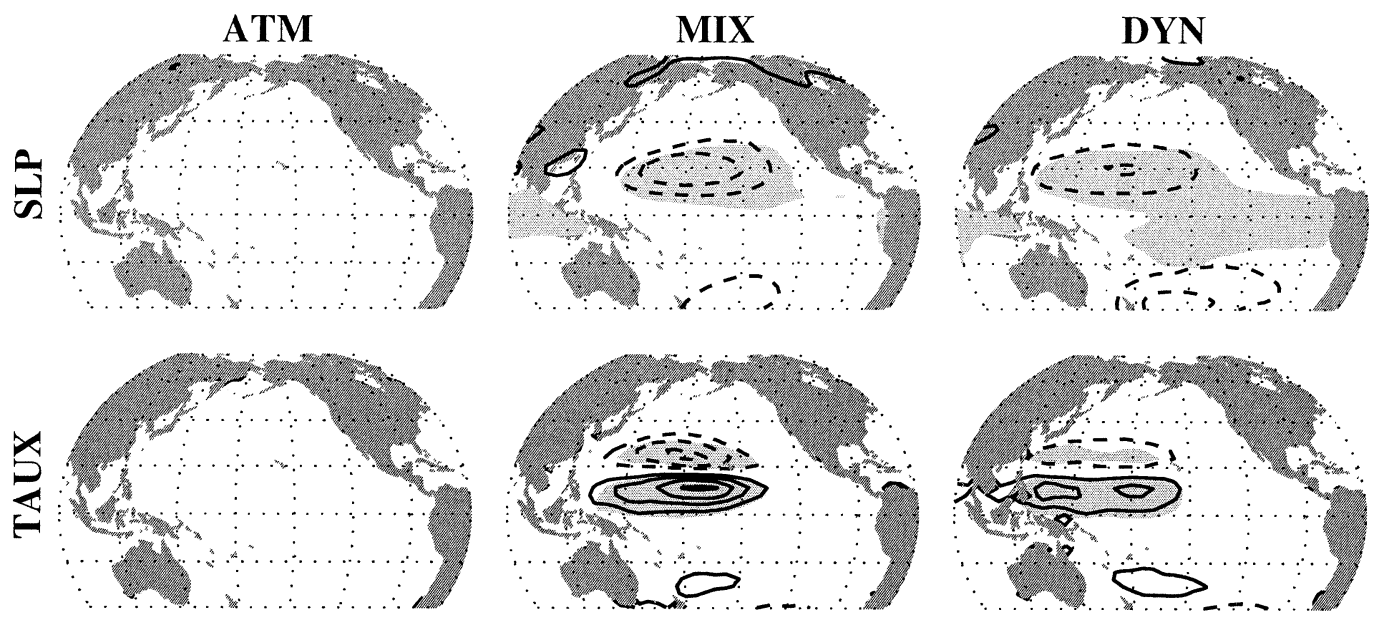

HFLX
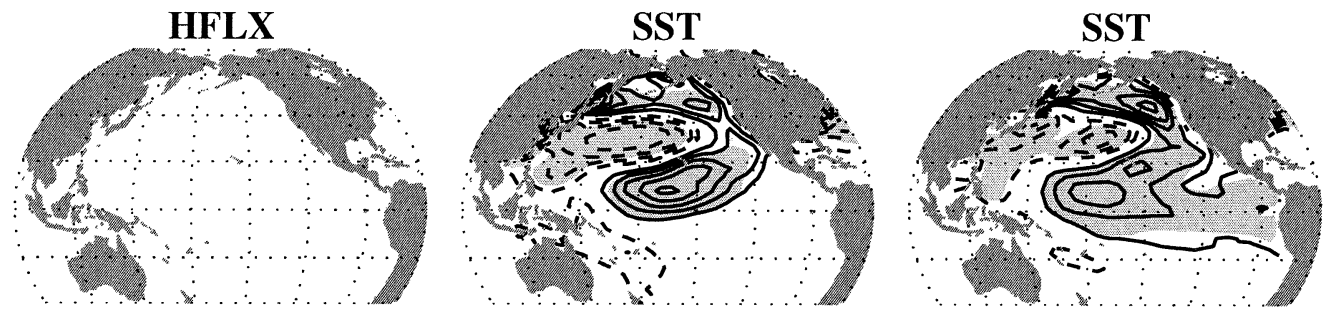

FIG. 5. Regressions of summer average (MJJAS) data onto the previous winter's PC1 from the (left) ATM, (middle) MIX, and (right) DYN simulations. Thus, Fig. 4 denotes conditions that occur simultaneously with PC1, and Fig. 5 denotes conditions during the following summer. (top) SLP, contour interval $0.2 \mathrm{hPa}$ (std dev) ${ }^{-1}$; (middle) zonal wind stress, contour interval $0.025 \mathrm{dyn} \mathrm{cm}^{-2}$ (std dev) ${ }^{-1}$; (bottom) net surface heat flux [ATM simulation, contour interval $3 \mathrm{~W} \mathrm{~m}^{-2}(\mathrm{std} \mathrm{dev})^{-1}$ ] and SST [MIX and DYN simulations, contour interval $0.075 \mathrm{~K}(\mathrm{std} \mathrm{dev})^{-1}$ ]. Light shading indicates regions where PC1 from the respective simulation explains more than $10 \%$ of the local variance of the respective data. Negative contours are dashed; the zero contour is omitted.

ENSO-like pattern found by VBH02 (cf. their Fig. 3), with warm anomalies stretching from about $150^{\circ} \mathrm{E}$ to the west coast of South America. The light shading in Fig. 5 indicates that $\mathrm{PC} 1$ from the DYN simulation explains more than $10 \%$ of the SST variance across the equatorial Pacific.

The regression maps in Figs. 4 and 5 identify the seasonal footprinting mechanism in linking winter NPO

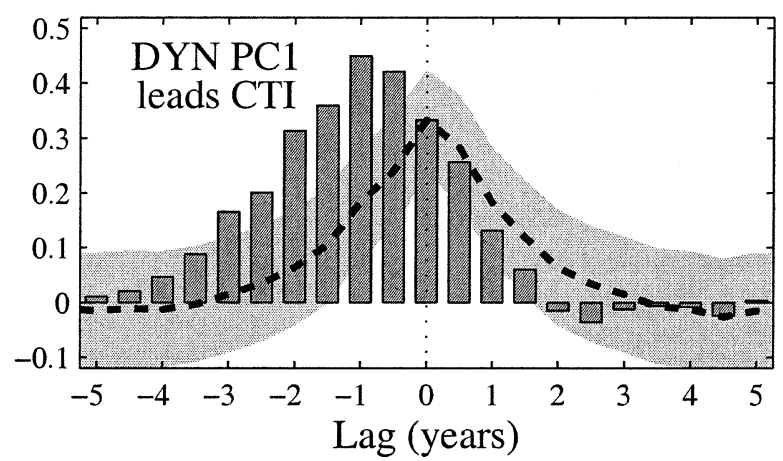

FIG. 6. Lagged correlation between DYN PC1 and the CTI (shaded bars), shown together with the atmospheric bridge null hypothesis (dashed line; see text), and 95\% confidence interval on the null hypothesis (shaded area). A lag of $-0.5(-1)$ indicates that the winter DYN PC1 index leads the following summer (winter) CTI. variability with tropical ENSO variability during the following summer. During winter, midlatitude atmospheric variability generates an SST footprint due to changes in the net surface heat flux (Fig. 4, bottom row). This SST footprint persists into the summer season (Fig. 5, MIX and DYN simulations). In the Tropics and subtropics, where the atmosphere is most sensitive to surface forcing, the SST footprint forces a residual atmospheric circulation that includes zonal wind stress anomalies that extend to the equator (Fig. 5, MIX and DYN simulations). Finally, the tropical coupled ocean-atmosphere system adjusts to these zonal wind stress anomalies producing an ENSO-like pattern of variability in the DYN simulation.

\section{b. Temporal relationships between the NPO and ENSO}

The regression maps in Figs. 4 and 5 establish a connection between the winter NPO and the development of tropical ENSO-like conditions during the following summer. To more explicitly investigate this connection, the lagged correlation between PC1 and the CTI is calculated for the DYN simulation and plotted in Fig. 6 . We note here that it is well established that tropical 
ENSO variability can force extratropical atmospheric teleconnections [the so-called atmospheric bridge; see Trenberth et al. (1998) and Alexander et al. (2002) for reviews]. Thus, the hypothesis that the NPO is influencing ENSO must be tested against a null hypothesis that assumes the existence of the atmospheric bridge (i.e., the null hypothesis assumes that tropical ENSO variability is forcing the NPO). This null hypothesis is taken from VBH01 and is the "automatic correlation" between PC1 and the CTI: it is expected that PC1 and the CTI will be correlated at lag $\tau$ simply because PC1 and the CTI are correlated at zero lag, and the CTI is autocorrelated with itself at lag $\tau$. This null hypothesis is written as

$$
r_{\mathrm{PC} 1, \mathrm{CTI}}^{\text {null }}(\tau)=r_{\mathrm{PC} 1, \mathrm{CTI}}(0) \times r_{\mathrm{CTI}, \mathrm{CTI}}(\tau) .
$$

The confidence interval on the null hypothesis is computed via a Fisher's $Z$ transformation (D. L. Hartmann 1998, personal communication), assuming an expected correlation via Eq. (1). Furthermore, the number of degrees of freedom is calculated by applying the method of Bretherton et al. (1999) to the winter CTI in accord with the null hypothesis (this leaves a very conservative 350 degrees of freedom between the two 1000-yr time series).

The lagged correlation between PC1 and the CTI, the null hypothesis, and the $95 \%$ confidence intervals on the null hypothesis are plotted for the DYN simulation in Fig. 6. For reference, a lag of $-0.5(-1)$ indicates that the winter DYN PC1 index leads the following summer (winter) CTI. The lagged correlation peaks when DYN PC1 leads the CTI by 1 yr $[r(-1)=0.45]$ and shows statistically significant differences from the null hypothesis when DYN PC1 leads the CTI by up to $3 \mathrm{yr}$. This lead is significant in both halves of the 1000yr data record. In contrast, the lagged correlation is indistinguishable from the null hypothesis for all positive lags (when the CTI leads DYN PC1). The strong asymmetry in the DYN simulation demonstrates that variability associated with the NPO is responsible for forcing tropical ENSO-like variability (cf. Figs. 4, 5).

To further examine the temporal relationship between the NPO and tropical ENSO variability we apply crossspectral analysis to MPC1 and the CTI from the MIX and DYN simulations (the variance spectra of these indices are plotted in Fig. 3). The cross-spectra are calculated using the same method as the spectra in Fig. 3. The squared coherence and phase relationship between MPC1 and the CTI for the MIX and DYN simulations are plotted in Fig. 7. For periods shorter than about 2$4 \mathrm{yr}$, coherence estimates for either simulation are generally weak. For periods longer than 2-4 yr, the squared coherence estimates in the MIX simulation are weak, though marginally significant. The lack of coherence likely relates to the meaninglessness of the CTI in the MIX simulation.

In the DYN simulation the squared coherence estimate between MPC1 and the CTI is quite large and a. Squared coherence
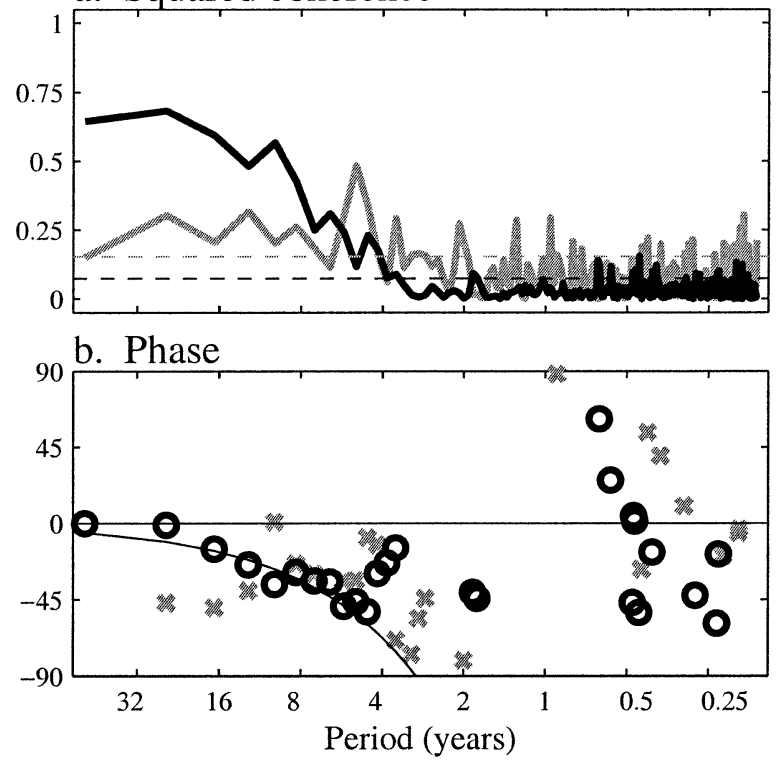

FIG. 7. Cross-spectral analysis between MPC1 and the CTI for the MIX simulation (solid gray line) and the DYN simulation (solid black lines): (a) squared coherence between MPC1 and the CTI, shown together with the 95\% confidence interval (thin dashed lines); (b) phase lag between MPC 1 and the CTI, indices (gray $\times$ 's and black circles represent the MIX and DYN simulations, respectively), shown together with an 8-month lag and the zero-lag line (thin lines). (b) Negative phases indicate that MPC1 leads the CTI.

significant for periods longer than about 4 yr. Furthermore, the phase lag between MPC1 and the CTI indicates that for timescales longer than about $4 \mathrm{yr}$, MPC1 leads the CTI in the DYN simulation. For reference, the phase for a constant lead of 8 months (chosen by visual inspection) is plotted as a thin solid line in Fig. $7 \mathrm{~b}$. There is a good fit between the 8-month lead curve and the phase estimates from the DYN simulation at the low frequencies where MPC1 and the CTI are coherent, indicating that at these frequencies the NPO tends to lead changes in the tropical ocean by about 8 months. The variance spectra of MPC1 and the CTI from the DYN simulation (see Fig. 3) explain an apparent contradiction between the 1-3-yr lead seen in the lagged correlation (Fig. 6) and the 8-month lead implied by the crossspectral analysis (Fig. 7b): because the decorrelation timescale of the DYN PC1 is much shorter than the DYN CTI's preferred timescale, the lagged correlation takes on the autocorrelation characteristics of the DYN CT index. Thus, the 8-month lead implied by the phase relationship is the physically meaningful relationship between the two time series.

\section{Physics of the SFM}

In this section we examine the physical mechanism behind the seasonal relationships outlined in section 4 . We begin in section $4 \mathrm{a}$ with an analysis of the heat flux components responsible for the generation of the SST 

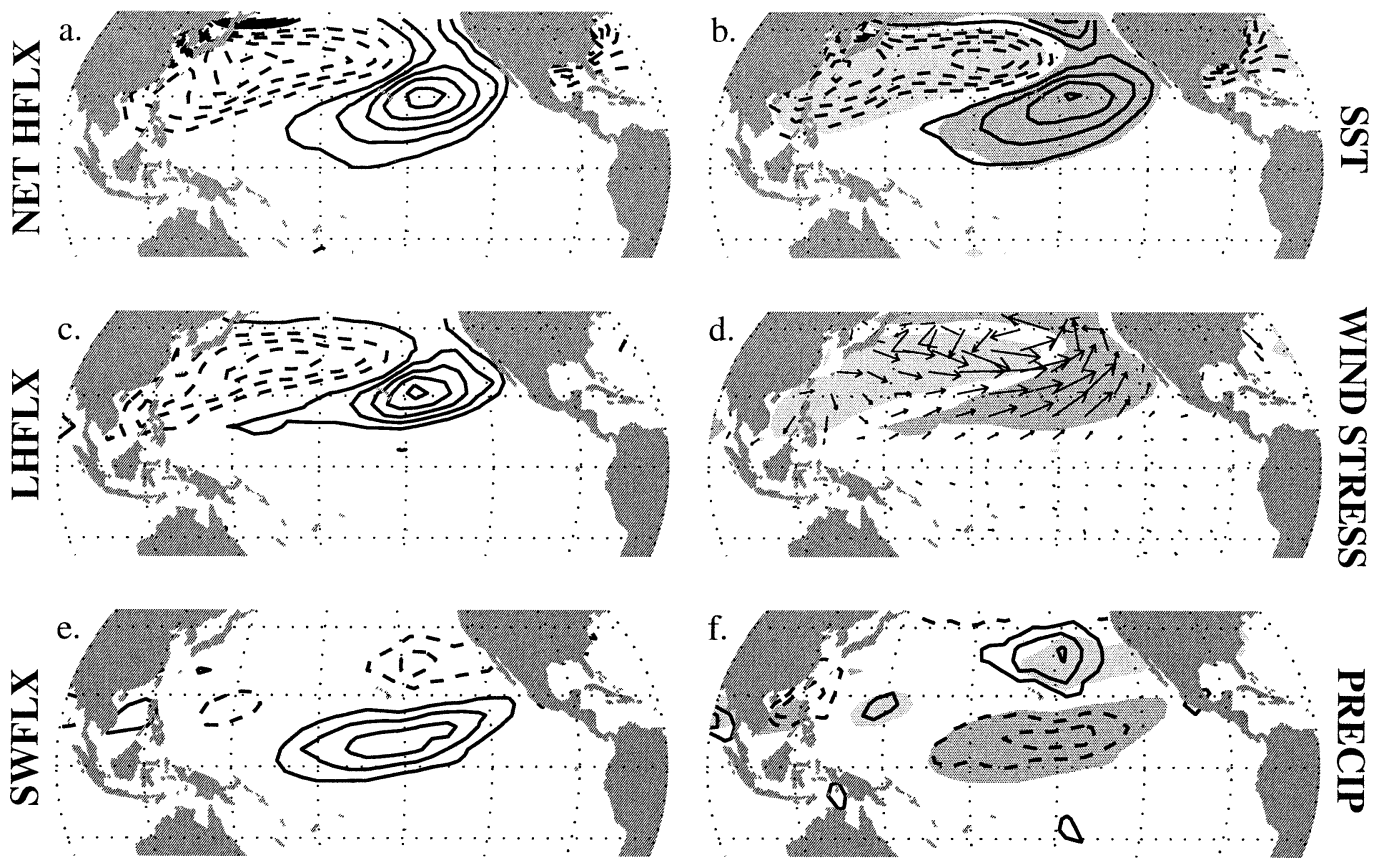

FIG. 8. Regressions of winter average (NDJFM) data onto MIX PC1: (a) net surface heat flux; (b) SST (contours) and net surface heat flux (shading); (c) latent heat flux; (d) surface wind stress [vectors; max $0.2 \mathrm{dyn} \mathrm{cm}^{-2}$ (std dev) $)^{-1}$ ] and latent heat flux (shading); (e) shortwave heat flux; (f) precipitation (contours) and shortwave heat flux (shading). In (a), (c), (e) the contour interval for the heat flux maps is $2 \mathrm{~W} \mathrm{~m}^{-2}$ (std dev) ${ }^{-1}$ (positive downward); in (b) the interval for SST is $0.075 \mathrm{~K}$ (std dev) $)^{-1}$; and in (e) the interval for precipitation is $0.2 \mathrm{~mm}$ day ${ }^{-1}(\mathrm{std} \mathrm{dev})^{-1}$. In (b), (d), (f) dark and light shading denote regions where the net, latent, or shortwave heat flux exceeds +2 or $-2 \mathrm{~W} \mathrm{~m}^{-2}$ $(\text { std dev })^{-1}$, respectively. Solid contours denote positive values; dashed contours denote negative values. The zero contour is omitted.

footprint during winter, and the atmospheric response to that footprint during summer. Next, in section $5 b$ the dynamic response of the ocean is inferred through closer examination of the structure of the zonal wind stress anomalies produced by the NPO during winter, and those produced through the SFM during the following summer. Finally, the month-by-month evolution of the SFM is examined in section $5 \mathrm{c}$.

\section{a. Generation of the SST footprint, and the atmospheric response}

The importance of SST anomalies in providing a link between the winter and summer seasons motivates a more detailed look at the individual heat flux components that contribute to the net surface heat flux in the MIX simulation. Figure 8 shows the regression maps of various data onto the standardized PC1 from the MIX simulation. The winter net heat flux and SST (Figs. 8a and 8 b, respectively) have nearly identical structures, with positive SST anomalies collocated with downward net heat flux anomalies. This relationship between SST and net heat flux confirms the relationship inferred from Fig. 4: the NPO is generating the SST footprint during winter in the MIX simulation. The winter net heat flux anomalies (Fig. 8a) are dominated by contributions from the latent and downward shortwave radiative fluxes
(Figs. 8c and 8e, respectively). In the midlatitudes the net heat flux is dominated by the latent heat flux. The structure of the latent heat flux, in turn, is consistent with inferred changes in the mean wind speed (Fig. 8b). Note especially the weakened trades in the subtropics west of the Baja California (Fig. 8d), that warm the surface via a reduction of the climatological upward latent heat flux from the surface (Fig. 8c). Equatorward of about $10^{\circ} \mathrm{N}$ the net surface heat flux is dominated by increased downward shortwave radiation (Fig. 8e), which results from decreased cloud cover and, hence, decreased planetary albedo (inferred from the precipitation anomalies contoured in Fig. 8f). The reduced tropical precipitation may in turn be attributed to reduced frictional convergence near the surface, due to the relaxation of the trades seen in Fig. 8d.

During summer, the physical mechanism responsible for the residual atmospheric response (seen in Fig. 5) is illuminated by the regression maps in Fig. 9. Like the winter maps, the summer net heat flux and SST maps (Figs. 9a and 9b, respectively) have similar spatial structures. (Differences between the spatial structure of equatorial SST and net heat flux anomalies near the date line will be discussed further in section 5c.) Note, however, that during the summer the local relationship between SST and net heat flux is reversed: positive SST anomalies are collocated with an upward net heat flux during 

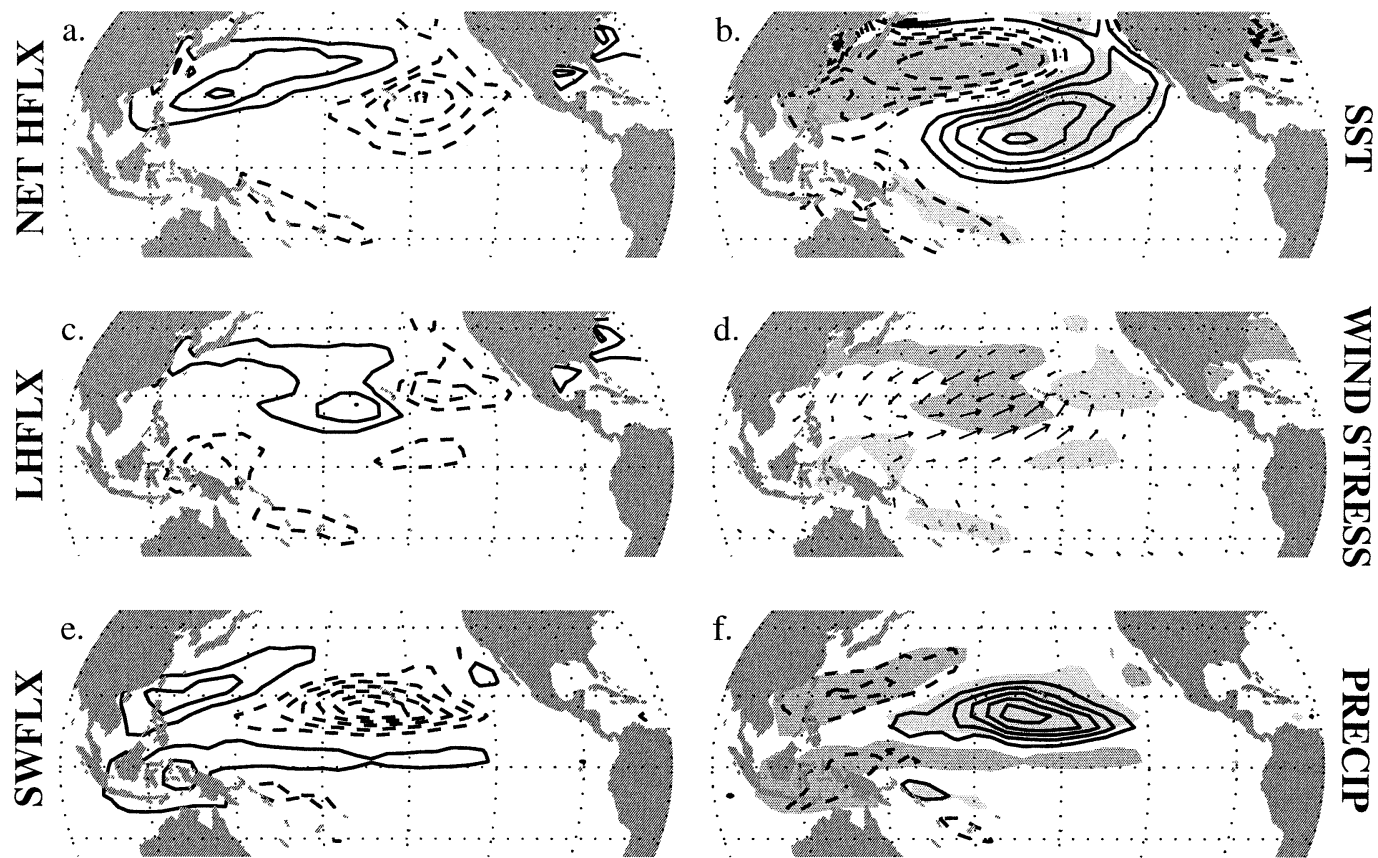

FIG. 9. Regressions of summer average (MJJAS) data onto MIX PC1: (a) net surface heat flux; (b) SST (contours) and net surface heat flux (shading); (c) latent heat flux; (d) surface wind stress [vectors; max $0.1 \mathrm{dyn} \mathrm{cm}^{-2}$ (std dev) ${ }^{-1}$ ] and latent heat flux (shading); (e) shortwave heat flux; (f) precipitation (contours) and shortwave heat flux (shading). In (a), (c), (e) the contour interval for the heat flux maps is $2 \mathrm{~W} \mathrm{~m}^{-2}$ (std dev) ${ }^{-1}$ (positive downward); in (b) the interval for SST is $0.075 \mathrm{~K}(\mathrm{std} \mathrm{dev})^{-1}$; and in (e) the interval for precipitation is $0.2 \mathrm{~mm}$ day $^{-1}\left(\mathrm{std} \mathrm{dev}^{-1}\right.$. In (b), (d), (f) dark and light shading denote regions where the net, latent, or shortwave heat flux exceeds +2 or $-2 \mathrm{~W} \mathrm{~m}^{-2}$ $(\text { std dev })^{-1}$, respectively. Solid contours denote positive values; dashed contours denote negative values. The zero contour is omitted.

summer, indicating that the ocean is damping to the atmosphere. The atmospheric response during summer consists of increased precipitation (Fig. 9f, solid contours) and the accompanying circulation anomalies previously discussed (evident in the SLP and zonal wind stress maps in Fig. 5 and Fig. 9d). In general, the atmospheric response during summer is consistent with the tropical atmospheric response to off-equatorial heating argued by Gill (1980) and by Hoskins and Karoly (1981). As argued by Hoskins and Karoly (1981), the surface heating by the subtropical SST footprint induces a strong northward meridional flow over the maximum SST anomalies (cf. Figs. 9b,d). This results in increased convergence centered slightly to the north of the maximum SST anomalies (as seen in the precipitation maps in Fig. 9f), and a surface cyclone centered to the north and west of the SST and precipitation anomalies (as seen in Fig. 5). A detailed investigation of the relative roles of surface and elevated heating (as in Chiang et al. 2001) is beyond the scope of this study. The SST footprint damps by latent heat flux anomalies and by reduced downward solar radiation (due to the precipitation anomalies in Fig. 9f). We note that a separate atmospheric GCM [the National Center of Atmospheric Research (NCAR) Community Climate Model version 3.6 in a configuration outlined in Yin and Battisti
(2001)] forced by the subtropical lobe of the SST footprint in Fig. 9b reproduces many of the elements of the summer atmospheric response in Figs. 5 and 9, including the westerly equatorial zonal wind stress anomalies.

The regression maps in Figs. 8 and 9 refine the mechanism discussed at the end of section 4a for the generation of the SST footprint during winter, and the residual atmospheric response during the following summer. During winter, the subtropical lobe of the NPO is associated with a weakening in the strength of the trades, which in turn reduces the frictional surface convergence into the Tropics. The weakened trades generate the SST footprint in the subtropics and Tropics through reduced upward latent heat fluxes and increased downward solar heat fluxes. The SST footprint persists beyond the lifetime of the NPO and, during summer, provides a source of surface heating for the tropical atmosphere. The tropical atmospheric response to that surface heating includes increased surface convergence (and positive precipitation anomalies) just north of the maximum SST anomalies, and a surface cyclone centered northwest of the maximum SST and precipitation anomalies. Along the southern flank of this this cyclone is the tongue of westerly zonal wind stress anomalies that will be shown to have a strong projection on the equatorial oceanic Kelvin wave in the following section. 


\section{MIX simulation}

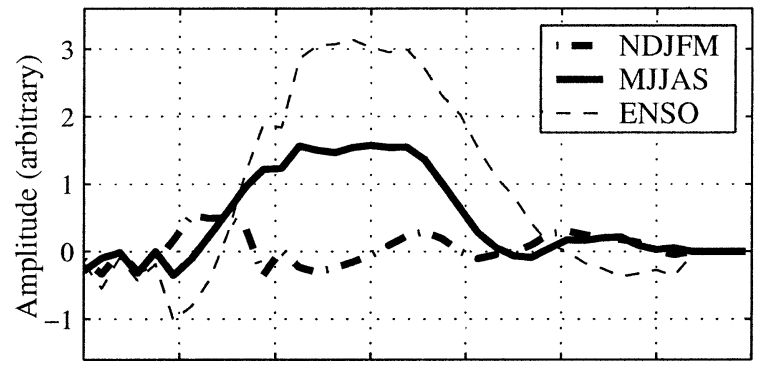

DYN simulation

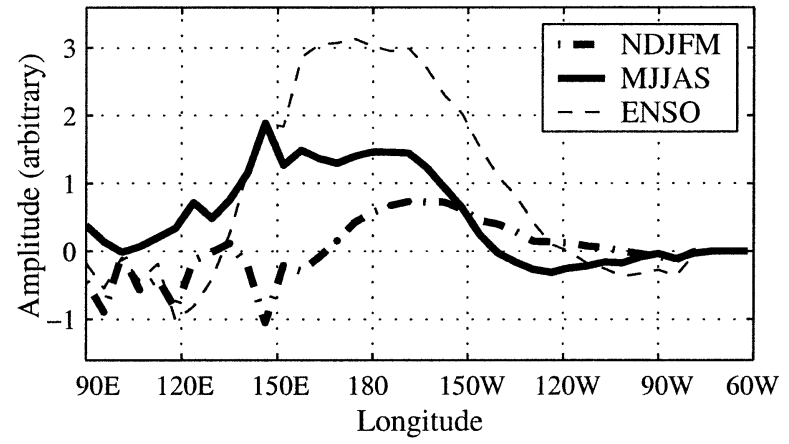

FIG. 10. Kelvin wave forcing function $K_{f}$ calculated for the regression maps of winter (thick dash-dot line) and summer (thick solid line) zonal wind stress (Figs. 4 and 5, respectively), as well as the regression map of DYN zonal wind stress onto the semiannual CTI from the DYN simulation (thin dashed line): (top) MIX and (bottom) DYN simulation. Units are arbitrary, though the amplitude of the three curves may be directly compared. See text for definition of $K_{f}$.

\section{b. Inferred tropical ocean dynamical response}

The tropical ocean dynamical response to the equatorial zonal wind stress anomalies is inferred by investigating the oceanic equatorial Kelvin wave forcing function $K_{f}$. The equatorial Kelvin wave forcing term $K_{f}$ is generated by projecting a given zonal wind stress regression map onto the meridional Kelvin wave structure (see Battisti 1988, for details): $K_{f}(x, n)=\int_{-\infty}^{\infty} \tau_{x}(x, y) \psi_{0} d y$, where $\psi_{0}$ is the meridional equatorial Kelvin wave structure, and $\tau_{x}(x, y)$ is the given zonal wind stress map. Results are generally insensitive to realistic values for the equivalent depth of the first baroclinic mode, used to calculate $\psi_{0}$. The Kelvin wave forcing function $K_{f}$ indicates the relative strength of the equatorial Kelvin wave forcing produced by a given zonal wind stress map, as a function of longitude. Scaling is such that positive values of $K_{f}$ indicate that the given zonal wind stress map will locally force a downwelling (eastward propagating) equatorial Kelvin wave, resulting in a warming of the equatorial Pacific (via upwelling processes) to the east of the forcing.

The Kelvin wave forcing function $K_{f}$ is calculated for the regression maps of winter and summer zonal wind stress onto PC1 from the MIX and DYN simulations (shown in Figs. 4 and 5) and plotted as a function of longitude in Fig. 10. For reference, $K_{f}$ is also calculated for the regression map of DYN zonal wind stress onto the semiannual CTI (divided from May-October and November-April) and plotted as a thin dashed line in Fig. 10. Thus, the thin dashed line indicates the $K_{f}$ amplitude that would be expected from the DYN simulation's ENSO and ENSO-like variability.

The structure of the winter and summer $K_{f}$ highlights the importance of the seasonal footprinting mechanism in forcing the tropical ocean. In both simulations the winter $K_{f}$ (thick dash-dot line in Fig. 10) is quite weak across the entire basin, consistent with the lack of equatorial zonal wind stress anomalies in Fig. 4. During the following summer, $K_{f}$ is considerably stronger, with amplitude that is about one-half that of the ENSO-related $K_{f}$. Thus, the summer tropical zonal wind stress anomalies, produced through the SFM, are essential for producing a strong equatorial ocean response. It is noted that despite the reduced amplitude of the zonal wind stress maps in the DYN simulation in Fig. 5 the summer $K_{f}$ is equal in amplitude to that from the MIX simulation. The similarity in $K_{f}$ amplitude may reflect subtle differences in the near-equatorial structure of the two wind stress maps, or may represent the positive Bjerknes feedback in the DYN simulation (as discussed by VBH02). In either case, these positive coupled feedbacks are likely responsible for the ENSO-like structure of the SST maps in the DYN simulation (in Fig. 5). It is noted that the first four symmetric Rossby wave forcing functions (calculated in a similar fashion as $K_{f}$ and scaled by a perfect western boundary reflection coefficient) are all quite weak for the same summer and winter wind stress regression maps used to calculate $K_{f}$.

\section{c. Month-by-month evolution of the SFM}

In section 4 , we found that equatorial zonal wind stress anomalies arise as a summer response to tropical and subtropical SST anomalies that are generated during the previous winter. In this section, we perform a more detailed analysis of the seasonality of this response by investigating the seasonality of zonally averaged tropical variability associated with the NPO in the MIX simulation. Maps in Fig. 11 are generated by regressing zonally averaged (over the region $150^{\circ} \mathrm{E}-135^{\circ} \mathrm{W}$ ) data for a given calendar month onto PC1 from the MIX simulation. Also shown is the regression coefficient of $K_{f}$ zonally averaged from $135^{\circ} \mathrm{E}-135^{\circ} \mathrm{W}$. A 3-month running mean is applied to each zonally averaged dataset in Fig. 11 prior to performing the regression. The resulting regression maps indicate the typical amplitude of zonally averaged variability at a given monthly lag, given one standard deviation of the MIX PC1 during the winter of year 0 .

The seasonal evolution of the SFM may be broken into two parts: the development of the SST footprint, and the response. The net heat flux regression coefficient (Fig. 11a, shading) indicates that the development of the SST footprint occurs primarily during the northern winter months, from November through March of year 

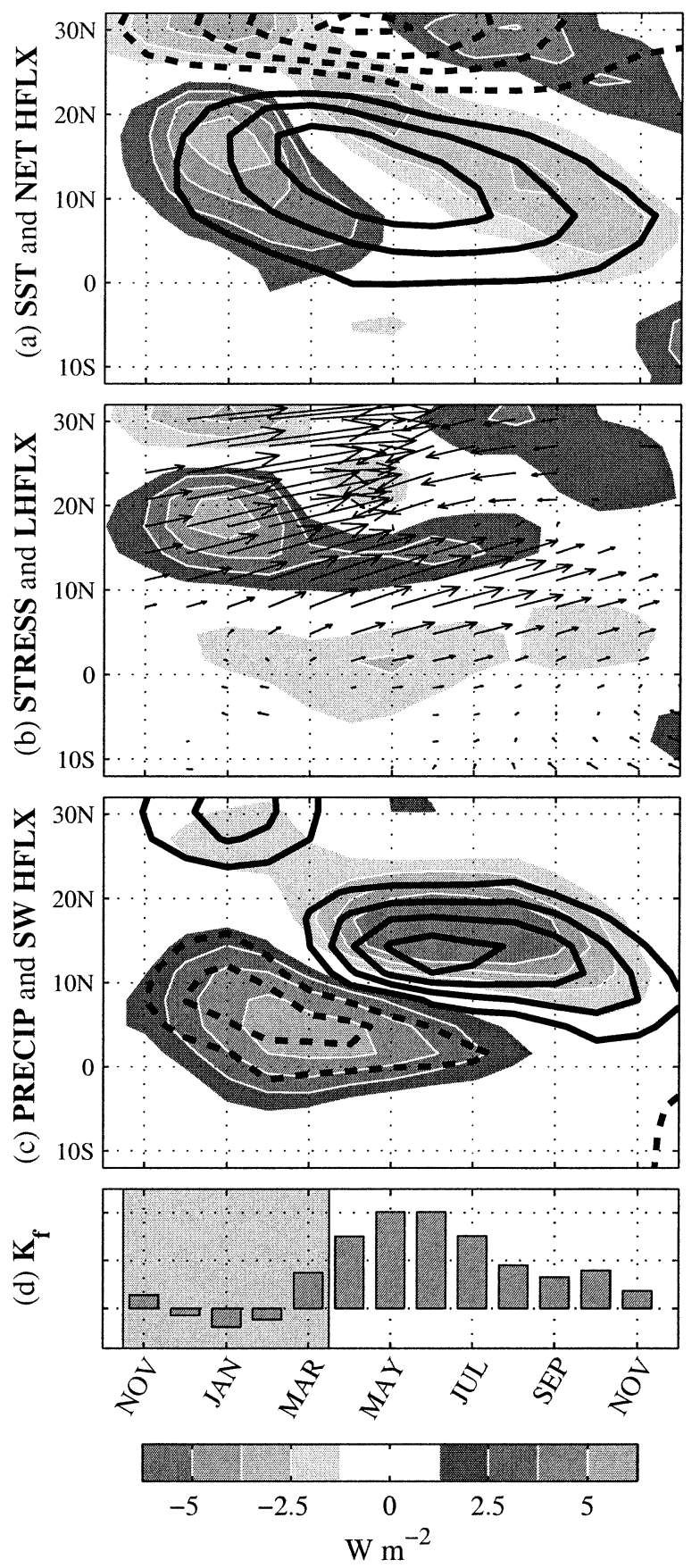

FIG. 11. Monthly evolution of the SFM: (a) net surface heat flux (shading) and SST [contour $0.075 \mathrm{~K}\left(\right.$ std dev) ${ }^{-1}$ ]; (b) latent heat flux (shading) and surface wind stress [vectors; max $0.2 \mathrm{dyn} \mathrm{cm}^{-2}$ (std dev $)^{-1}$ ]; (c) downward shortwave radiation (shading) and precipitation [contour $0.15 \mathrm{~mm} \mathrm{day}{ }^{-1}(\mathrm{std} \mathrm{dev})^{-1}$ ]; (d) $K_{f}$ averaged from $135^{\circ} \mathrm{E}$ to $135^{\circ} \mathrm{W}$ (arbitrary amplitude). In (a)-(c) data are zonally averaged over the longitudinal band $150^{\circ} \mathrm{E}-135^{\circ} \mathrm{W}$. Plotted is the lagged regression coefficient of each variable (as a function of month) onto MIX PC1. A 3-month running mean has been applied to the data prior to calculating the regressions. Shading in (d) denotes the months over which MIX PC1 is defined (NDJFM).
0. This is consistent with Fig. 2, which indicates that the NPO pattern is most energetic during these months. During this time, the net surface heat flux warms the tropical and subtropical ocean via changes in the latent and shortwave heat fluxes (shading in Figs. 11b and $11 \mathrm{c}$, respectively). The subtropical portion of the SST footprint (Fig. 11a, contours) peaks in late spring and early summer (April-June). Of interest is the southward progression of net surface heat flux and SST anomalies evident in the top panel of Fig. 11, consistent with the spatial maps in Figs. 4 and 5. This southward progression will be discussed in more detail shortly.

The atmospheric response to the SST footprint is clear during the northern spring and summer months in the bottom three panels of Fig. 11. The wind stress (vectors in Fig. 11b) exhibits a generally cyclonic circulation centered at about $17.5^{\circ} \mathrm{N}$ from April until about October or November. In the deep Tropics these wind stress anomalies extend south of the equator. The development and decay of $K_{f}$ (Fig. 11d) occurs in phase with the SST footprint, with a maximum $K_{f}$ occurring during May and June, and positive values of $K_{f}$ continuing into the following November. It is noted that $K_{f}$ appears more closely tied to SST than to the net surface heat flux. The seasonal evolution of $K_{f}$ indicates that the response to the SST footprint is not entirely confined to the summer season but rather is a continual response to the SST footprint of the NPO.

In addition to illustrating the seasonality of the SFM, Fig. 11 identifies some interesting positive feedbacks between the atmospheric response to the SST footprint and the evolution of the SST footprint itself. Most notable is the persistence and southward development of the positive lobe of the SST footprint in Fig. 11a. Near $15^{\circ} \mathrm{N}$, a positive feedback between the latent heat flux and the SST (Figs. 11b and $11 \mathrm{a}$, respectively) is observed from March until about September, where downward latent heat flux anomalies are coincident with warm SSTs. The latent heat flux may in turn be separated via a standard bulk formulation into a component caused by changes in the surface wind speed, and a component caused by changes in the near-surface specific humidity gradient. The relationship between the latent heat flux and the surface wind stress in Fig. 11b qualitatively suggests that the weakened trades act to produce a downward latent heat flux anomaly that may increase the persistence of the SST footprint. Still, warming by the anomalous latent heat flux near $15^{\circ} \mathrm{N}$ is much weaker than the cooling caused by the reduced downward solar radiation, and the net effect is a damping of the SST footprint. In the deep Tropics (near the equator) the reduced wind speed does not appear sufficient to counter the increased vertical specific humidity gradient (due to the increased SST), and the latent heat flux acts to damp the SST footprint.

An additional positive feedback is qualitatively seen in the development of precipitation and shortwave radiation in Fig. 11c. After March, the residual atmo- 
spheric response to the SST footprint includes divergence away from the deep Tropics (inferred from the wind stress in Fig. 11b). This results in reduced precipitation between the equator and about $7.5^{\circ} \mathrm{N}$, and increased downward solar radiation. This effect persists throughout the entire summer and may be responsible for the apparent southward migration of SST anomalies in Fig. 11a. Further analysis is needed to quantitatively determine the nature and strength of feedbacks between the SST footprint and the residual atmospheric circulation that it forces.

\section{Conclusions and discussion}

\section{a. Conclusions and caveats}

The role of the SFM in linking midlatitude atmospheric variability and tropical ENSO variability is examined in the CSIRO CGCMs. The analysis herein confirms the basic physics behind the SFM (set forth by VBH01). To reiterate, midlatitude atmospheric variability (with a spatial structure that resembles the NPO) imparts an SST footprint onto the ocean. The SST footprint persists into the following spring and summer, and in the subtropics and Tropics, it forces a residual atmospheric circulation that includes zonal wind stress anomalies along the equator. The Tropics respond to these equatorial zonal wind stress anomalies through coupled dynamical feedbacks (discussed in VBH02), producing an ENSO-like pattern of variability.

Details of the SFM are investigated in more detail than was possible in VBH01. Most notably, this investigation highlights the important role of weakened trades in generating the subtropical portion of the SST footprint. North of about $10^{\circ} \mathrm{N}$, the weakened trades warm the surface via a reduction of the climatological upward latent heat flux at the surface. Equatorward of $10^{\circ} \mathrm{N}$, the weakened trades are associated with reduced frictional convergence, reduced precipitation, and increased downward solar radiation at the surface via an inferred decrease in the local planetary albedo. Further analysis suggests a weak positive coupled feedback between the SST footprint and the residual circulation it forces.

Through the SFM, atmospheric variability intrinsic to the midlatitudes becomes a strong forcing on the coupled tropical system in the CSIRO model. Most notably, it is shown that the equatorial zonal wind stress anomalies produced through the SFM have a large projection onto the oceanic equatorial Kelvin wave, though the wind stress anomalies associated with the wintertime NPO have a very weak projection. These summer equatorial zonal wind stress anomalies appear to be an important component of the stochastic forcing essential for maintaining variance of the DYN simulation's linearly damped ENSO mode (VBH02). Based on the crossspectral analysis in Fig. 7, the SFM appears to explain $20 \%-40 \%$ of the DYN simulation's tropical interannual ENSO variability and nearly $70 \%$ of the tropical decadal to interdecadal ENSO-like variability in the DYN simulation.

We note that the CSIRO models may overemphasize the role of the SFM in producing tropical variability. First, the depth of the oceanic mixed layers in the MIX and DYN simulations are constrained to $50 \mathrm{~m}$. In the DYN simulation, this constraint comes about through the minimum vertical diffusivity in the ocean model's upper levels (see section 2). Observed summer mixedlayer depths are often much more shallow than $50 \mathrm{~m}$, reducing the persistence of SST anomalies generated during the previous winter. Second, due to coarse resolution, interannual ENSO variability in the DYN simulation is heavily damped. It remains to be seen what effect the SFM will have in models with less stable, or even unstable ENSO modes. We reiterate that the stability of the ENSO mode in nature is unknown.

\section{b. Discussion}

The existence of the SFM raises several questions relating to the interpretation of midlatitude and tropical variability. We address these questions in the remainder of this section.

How does the SFM affect the interpretation of midlatitude variability? In general, midlatitude variability may be separated into intrinsic midlatitude variability (e.g., Hasselmann 1976) and tropically forced midlatitude variability [the so-called atmospheric bridge discussed by Alexander et al. (2002) and references therein]. A common technique for distinguishing between intrinsic and tropically forced midlatitude variability has been through the removal of the tropically forced variability from the midlatitudes via linear regression (e.g., Zhang et al. 1996, 1997). This technique cannot distinguish between midlatitude variability that is tropically forced and intrinsic midlatitude variability that may be forcing the Tropics. The removal of tropically forced midlatitude variability is partially justified by the time lag inherent to the SFM (the atmospheric response to tropical forcing is instantaneous). Still, care should be taken when distinguishing between tropically forced and intrinsic midlatitude variability over long timescales.

Is the atmospheric connection hypothesized in Barnett et al. (1999) or Pierce et al. (2000) any different than the SFM? Barnett et al. (1999) and Pierce et al. (2000) use 10-yr low-pass-filtered, annually averaged data to hypothesize that the atmosphere directly connects midlatitude atmospheric variability to tropical zonal wind stress anomalies. The same might be concluded based only on the results of section 3 from VBH01. However, results from sections 4 and 5 herein indicate that the mechanism connecting midlatitude atmospheric variability to tropical zonal wind stress depends critically on coupling between the tropical and subtropical atmosphere and oceanic mixed layer, a result that is seen most clearly in seasonally averaged data. Based on the findings herein, we speculate that the atmospheric con- 
nection between the midlatitudes and Tropics hypothesized in Barnett et al. (1999) and in Pierce et al. (2000) is governed by the mechanism outlined herein. However, further analysis is needed to confirm the presence of the SFM in their models.

Do other modes of northern midlatitude atmospheric variability affect the Tropics through a mechanism like the SFM? The second mode of midlatitude atmospheric variability (which represents variability in the Aleutian low-PNA) has a small, but significant, correlation with the CTI one-half year in advance. Like the NPO, the Aleutian low covaries with reduced trade wind strength and, hence, appears capable of generating weak subtropical SST anomalies that produce a similar residual response as seen in section 4. Unlike the NPO, the largest values of $K_{f}$ occur during winter instead of summer. Further research is needed to identify the causal relationship between the Aleutian low and ENSO in the CSIRO models.

Is there an analog to the SFM in regions outside the North Pacific? The general features of the SFM need not be confined to the North Pacific. Indeed, Watterson (2001) find that footprinted SST anomalies affect the structure of the Southern Hemisphere zonal vacillation in the CSIRO CGCMs.

We briefly investigated the effect of Southern Hemisphere atmospheric variability on tropical variability (via the SFM) in the CSIRO CGCMs. Analysis of Southern Hemisphere atmospheric variability and tropical coupled variability in the CSIRO CGCMs (similar to the analysis carried out in section 4) indicates that, unlike the Northern Hemisphere, Southern Hemisphere atmospheric variability has very little effect on the Tropics. We speculate that the influence of Southern Hemisphere midlatitude atmospheric variability on the Tropics is weak because (a) patterns of Southern Hemisphere midlatitude atmospheric variability do not force SST anomalies that extend to the deep Tropics, and (b) the atmosphere in the southern tropical Pacific is not as sensitive to SST anomalies as is the northern tropical Pacific (possibly due to colder mean SSTs in the southern Tropics).

What implications does the SFM have for predictability in the Tropics and for predictability of ENSO? The SFM is an attractive candidate to affect the evolution, and hence predictability, of ENSO. First, the tropical component of the SST footprint and its accompanying equatorial zonal wind stress anomalies persist for several months. Thus, unlike atmospheric phenomenon, such as the Madden-Julian oscillation, footprinting provides a persistent forcing in the tropical waveguide, which may elicit a stronger response in the tropical ocean. Second, the atmospheric response to the SST footprint is strongest through the spring and summer seasons, when the coupling between the atmosphere and ocean in the equatorial Pacific is strongest and the coupled system is most sensitive (Thompson and Battisti 2001).
In a companion manuscript Vimont et al. (2003) find that through the SFM, midlatitude atmospheric variability may play an important role in the stochastic forcing of ENSO in nature. Furthermore, they find significant skill when midlatitude atmospheric variability (with a spatial structure that closely resembles the NPO) is used to predict ENSO a year in advance (a crossvalidated prediction scheme that uses the NPO to predict ENSO during the following winter yields a correlation of 0.46 over the interval 1949-2001). Further research is needed to identify the details and the importance of the SFM in generating and predicting ENSO variability in models and in nature.

Acknowledgments. Special thanks to E. S. Sarachik and J. M. Wallace at the University of Washington for their support and guidance. We are grateful to A. Miller, S. Schubert, I. Watterson, and three anonymous reviewers for their suggestions and conversations during the course of this work. Thanks also to M. Collier for preparing and providing the model data. This publication is supported by a grant to the Joint Institute for the Study of the Atmosphere and Ocean (JISAO) under NOAA Cooperate Agreement NA17RJ1232.

\section{REFERENCES}

Alexander, M. A., I. Bladé, M. Newman, J. R. Lanzante, N.-C. Lau, and J. D. Scott, 2002: The atmospheric bridge: The influence of ENSO teleconnections on air-sea interaction over the global oceans. J. Climate, 15, 2205-2231.

Barnett, T. P., D. W. Pierce, M. Latif, D. Dommenget, and R. Saravanan, 1999: Interdecadal interactions between the Tropics and midlatitudes in the Pacific basin. Geophys. Res. Lett., 26, 615618.

Barsugli, J. J., and D. S. Battisti, 1998: The basic effects of atmosphere-ocean thermal coupling on midlatitude variability. J. Atmos. Sci., 55, 477-493.

Battisti, D. S., 1988: Dynamics and thermodynamics of a warming event in a coupled tropical atmosphere-ocean model. J. Atmos. Sci., 45, 2889-2919.

Bladé, I., 1997: The influence of midlatitude ocean-atmosphere coupling on the low-frequency variability of a GCM. Part I: No tropical SST forcing. J. Climate, 10, 2087-2106.

__ 1999: The influence of midlatitude ocean-atmosphere coupling on the low-frequency variability of a GCM. Part II: Interannual variability induced by tropical SST forcing. J. Climate, 12, 2145 .

Bretherton, C. S., M. Widmann, V. P. Dymnikov, J. M. Wallace, and I. Bladé, 1999: The effective number of spatial degrees of freedom of a time-varying field. J. Climate, 12, 1990-2009.

Chang, P., L. Ji, H. Li, and M. Flügel, 1996: Chaotic dynamics versus stochastic processes in El Niño-Southern Oscillation in coupled ocean-atmosphere models. Physica D, 98, 301-320.

Chiang, J. C. H., S. Zebiak, and M. A. Cane, 2001: Relative roles of elevated heating and surface temperature gradients in driving anomalous surface winds over tropical oceans. J. Atmos. Sci., 58, 1371-1394.

Cox, M. D., 1984: A primitive equation, 3-dimensional model of the ocean. GFDL Ocean Group Tech. Rep. 1, GFDL-Princeton University, 141 pp. [Available from NOAA/Geophysical Fluid Dynamics Laboratory, Princeton University, Princeton, NJ 08542.]

Gargett, A. E., 1984: Vertical eddy diffusivity in the ocean interior. J. Mar. Res., 42, 359-393. 
Gent, P. R., and J. C. McWilliams, 1990: Isopycnal mixing in ocean circulation models. J. Phys. Oceanogr., 20, 150-155.

Gershunov, A., and T. P. Barnett, 1998: Interdecadal modulation of ENSO teleconnections. Bull. Amer. Meteor. Soc., 79, 27152726.

Gill, A. E., 1980: Some simple solutions for heat-induced tropical circulation. Quart. J. Roy. Meteor. Soc., 106, 447-462.

Gordon, H. B., and S. P. O'Farrell, 1997: Transient climate change in the CSIRO coupled model with dynamic sea ice. Mon. Wea. Rev., 125, 875-907.

Hasselmann, K., 1976: Stochastic climate models. I. Theory. Tellus, 28, 473-485.

Hirst, A. C., S. P. O'Farrell, and H. B. Gordon, 2000: Comparison of a coupled ocean-atmosphere model with and without oceanic eddy-induced advection. Part I: Ocean spinup and control integrations. J. Climate, 13, 139-163.

Hoskins, B. J., and D. J. Karoly, 1981: The steady linear response of a spherical atmosphere to thermal and orographic forcing. $J$. Atmos. Sci., 38, 1179-1196.

Hsu, H.-H., and J. M. Wallace, 1985: Vertical structure of wintertime teleconnection patterns. J. Atmos. Sci., 42, 1693-1710.

Mantua, N. J., S. R. Hare, Y. Zhang, J. M. Wallace, and R. C. Francis, 1997: A Pacific interdecadal climate oscillation with impacts on salmon production. Bull. Amer. Meteor. Soc., 78, 1069-1079.

Moore, A. M., and R. Kleeman, 1999: Stochastic forcing of ENSO by the intraseasonal oscillation. J. Climate, 12, 1199-1220.

Neelin, J. D., D. S. Battisti, A. C. Hirst, F. Jin, Y. Wakata, T. Yamagata, and S. E. Zebiak, 1998: ENSO theory. J. Geophys. Res., 103, 14 261-14 290.

Ng, M. K. F., and W. W. Hsieh, 1994: The equatorial Kelvin wave in finite difference models. J. Geophys. Res., 99, 14 173-14 185.

O'Farrell, S. P., 1998: Investigation of the dynamic sea ice component of a coupled atmosphere-sea ice general circulation model. $J$. Geophys. Res., 103 (C8), 15 751-15 782.

Penland, C., and P. D. Sardeshmukh, 1995: The optimal growth of tropical sea surface temperature anomalies. J. Climate, 8, 19992024.

Pierce, D. W., T. P. Barnett, and M. Latif, 2000: Connections between the Pacific Ocean Tropics and midlatitudes on decadal timescales. J. Climate, 13, 1173-1194.

Rogers, J. C., 1981: The North Pacific Oscillation. J. Climatol., 1, $39-57$.

Saravanan, R., 1998: Atmospheric low-frequency variability and its relationship to midlatitude SST variability: Studies using the NCAR Climate System Model. J. Climate, 11, 1386-1404.

Schopf, P. S., and M. J. Suarez, 1988: Vacillations in a coupled oceanatmosphere model. J. Atmos. Sci., 45, 549-566.

Thompson, C. J., and D. S. Battisti, 2000: A linear stochastic dynamical model of ENSO. Part I: Model development. J. Climate, 13, 2818-2832.

—_ and — 2001: A linear stochastic dynamical model of ENSO. Part II: Analysis. J. Climate, 14, 445-466.

Trenberth, K. E., G. W. Branstator, D. Karoly, A. Kumar, N.-C. Lau, and C. Ropelewski, 1998: Progress during TOGA in understanding and modelling global teleconnections associated with tropical sea surface temperatures. J. Geophys. Res., 103, 14 291-14 324.

Vimont, D. J., D. S. Battisti, and A. C. Hirst, 2001: Footprinting: A seasonal connection between the Tropics and mid-latitudes. Geophys. Res. Lett., 28, 3923-3926.

$[$ - - and $—, 2002$ : Pacific interannual and interdecadal equatorial variability in a 1000-yr simulation of the CSIRO coupled general circulation model. J. Climate, 15, 160-178.

— - J. M. Wallace, and D. S. Battisti, 2003: The seasonal footprinting mechanism in the Pacific: Implications for ENSO. $J$. Climate, 16, 2668-2675.

Walker, G. T., and E. W. Bliss, 1932: World weather V. Mem. Roy. Meteor. Soc., 4, 53-84.

Wallace, J. M., E. M. Rasmusson, T. P. Mitchell, V. E. Kousky, E. S. Sarachik, and H. von Storch, 1998: On the structure and evolution of ENSO-related climate variability in the tropical Pacific: Lessons from TOGA. J. Geophys. Res., 103, 14 241-14 259.

Watterson, I. G., 2001: Wind-induced rainfall and surface temperature anomalies in the Australian region. J. Climate, 14, 1901-1922.

__ S. P. O'Farrell, and M. R. Dix, 1997: Energy and water transport in climates simulated by a general circulation model that includes dynamic sea ice. J. Geophys. Res., 102, $11027-11037$.

Yin, J. H., and D. S. Battisti, 2001: The importance of tropical sea surface temperature patterns in simulations of last glacial maximum climate. J. Climate, 14, 565-581.

Zebiak, S. E., and M. A. Cane, 1987: A model ENSO. Mon. Wea. Rev., 115, 2262-2278.

Zhang, C., H. H. Hendon, W. S. Kessler, and A. J. Rosati, 2001: A workshop on the MJO and ENSO. Bull. Amer. Meteor. Soc., 82, 971-976.

Zhang, Y., J. M. Wallace, and N. Iwasaka, 1996: Is climate variability over the North Pacific a linear response to ENSO? J. Climate, 9, 1468-1478.

—_ - and D. S. Battisti, 1997: ENSO-like interdecadal variability: 1900-93. J. Climate, 10, 1004-1020. 